\title{
El papiamento: un tesoro lingüístico
}

Palabras clave: papiamento, criollo, historia, análisis del texto, Кompa Nanzi.

\section{Historia, origen y evolución}

Papiamento, una lengua criolla que fue descubierta por los lingüistas hace muy poco y que, hablando no sólo lingüísticamente, esconde un enorme tesoro ya que cada elemento que lo integra nos revela una pieza de la historia. Este criollo tan peculiar llegó a intrigar a grandes lingüistas como Rodolfo Lenz, Friedrich Diez y Hugo Schuchardt, entre los más eminentes. Actualmente, hay cada vez más científicos que se interesan por estudiarlo y entre ellos sobresalen Dan Munteanu, Bart Jacobs, John Lipski, para enumerar únicamente a algunos.

El gran autor curazaleño Frank Martinus Arion (2011: 198), quien en su obra literaria Dubbelspel pone en boca de uno de los personajes una posible definición del papiamento, dice: «voor zichzelf trachtte bij na te gaan uit boeveel talen bet Papiaments wel bestond: Afrikaans, Portugees, Spaans, Frans...» ${ }^{1}$. El autor culmina la oración con puntos suspensivos y tiene mucha razón en hacerlo ya que se trata de una lengua criolla integrada por elementos arahuaco-taínos, españoles, holandeses, africanos, portugueses, gallegos, franceses, ingleses, y seguramente por alguno más.

Para entender mejor esta lengua, su origen y forma de nacimiento tenemos que viajar al otro lado del Atlántico para ubicarnos más o menos a 80 kilómetros al norte de la costa venezolana a la altura del Estado Falcón donde se

1 La traducción del holandés es mía: «intentaba descubrir de cuántas lenguas estaba compuesto el papiamento: africano, portugués, español, francés...» 
sitúan tres islas caribeñas, pertenecientes al Reino de Países Bajos: Aruba, Bonaire y Curazao. Son islas habitadas por aproximadamente 230.000 personas y donde, como segunda lengua oficial (aparte del holandés), hablan el papiamento, una lengua criolla que nació en los albores del siglo XVII en la isla más grande, en Curazao. Para obtener una idea sobre cómo surgió el papiamento hay que volver siglos atrás, al año 1499 cuando Alonso de Ojeda, un navegante español que acompañaba a Colón, descubrió estas islas habitadas por caquetíos que habitaban las islas ya desde los años 2.800 a 2.300 antes de Cristo. En 1527 fueron integradas a la Corona española, imponiéndoles a sus habitantes la lengua castellana y la religión cristiana. Sin embargo, los españoles, que llegaron buscando oro y otras riquezas, al no encontrarlos en ninguna de las tres islas las denominaron Las islas inútiles y prácticamente sin lucha las cedieron a los holandeses que las colonizaron en 1634 por su posición estratégica y por las riquezas naturales que poseían, como la sal y la madera. Pero muy pronto estos recursos ya no les bastaban así que hacia 1647 convirtieron la mayor de las islas, Curazao, en un puerto de trata de esclavos africanos. Existen documentos que testimonian que entre 1700 y 1715 llegaban anualmente entre 3.500 y 4.000 esclavos a Curazao en calidad de ser vendidos como mano de obra barata y es así como «paulatinamente, el negro africano se extendió de Las Antillas al continente, y pronto todas las tierras conquistadas eran testigo de su presencia» (López Morales, 1998: 81). La Compañía de las Indias Occidentales de los holandeses gozaba de los beneficios de un negocio lucroso que suscitó envidia entre los demás conquistadores franceses, españoles, ingleses y portugueses, hecho que posteriormente provocó luchas entre los diferentes países europeos, haciendo que las islas pasaran de mano en mano de diferentes terratenientes mientras que los barcos llenos de esclavos seguían llegando de la costa occidental de África. Se estima que, para cuando terminó la trata en el año 1886, había llegado un total de nueve millones de esclavos al Nuevo Mundo. Pero antes de exponer las posteriores conquistas y reconquistas hay que subrayar un hecho sumamente importante que tuvo un gran impacto, lingüística y culturalmente hablando, para el criollo en cuestión. En 1659 llegaron las primeras olas migratorias de sefardíes de Ámsterdam y de Brasil, que eran, nada más y nada menos, descendientes de algunos de los judíos que habían sido expulsados en 1492 por los Reyes Católicos de España. Una gran parte de ellos se refugió en Portugal. Sin embargo, no duró mucho que el rey portugués Manuel I siguiera el ejemplo de los Reyes Católicos, desterrando de sus tierras a los sefardíes quienes se vieron obligados a marcharse. Así, forzados una vez más de irse, unos se instalaron en Holanda, mientras que otros 
en Brasil, y, cuando tampoco eran bienvenidos allí, muchos de ellos emigraron a Curazao que les acogió con los brazos abiertos. Los sefardíes llegaron a representar entre un 30 y $50 \%$ de la población blanca de las islas en aquel periodo, hecho que les concedía un poder notable, ya que el estatus social dependía del color de la tez. Estos judíos blancos además hablaban español o portugués, y muchos incluso ambas lenguas, hecho que enriqueció el léxico del papiamento con injertos ibéricos.

Posteriormente las islas pasaron a manos de los franceses por un periodo de cinco años, entre 1795 y 1800 y después empezaron a formar parte del protectorado británico. La Paz de Amiens, celebrada en 1802 y refrendada por los tratados de París en 1815, hizo que las islas volvieran a formar parte de la Corona holandesa, lo cual hasta el día de hoy ya no ha cambiado. Pero, a pesar de no pertenecer a la Corona española desde hace siglos, los contactos entre las islas y las tierras hispanohablantes en realidad nunca se han interrumpido debido a la cercanía de los países de habla hispana, gracias a matrimonios mixtos, debido a numerosos inmigrantes hispanoamericanos en las islas o a causa de emigraciones a países e islas vecinas que prometían una calidad de vida mejor por el trabajo que ofrecían.

Con lo que este crisol tan único de convivencia, a veces forzosa, de personas tan distintas creó una situación desigual para el español que permaneció en las islas como lengua que desterró el arahuaco-taíno, olvidado por Alonso de Ojeda y sus hombres, que al transcurrir los siglos dio a luz al papiamento. El primer documento conservado, que suele ser el objeto de referencia como el primero, data de 1830 y se trata de un poema anónimo encontrado en Puerto Rico. Sin embargo, existe una carta más antigua escrita por Abraham da Costa Andrade a Sarah de Isaac Pedro y Vaz Farro de 1775, hallada en Curazao. Desde su cuna, Curazao, el papiamento se extendió a las dos islas vecinas, primero a Bonaire ${ }^{2}$ y posteriormente a Aruba. Al principio, un mero pidgin que servía como herramienta para posibilitar la comunicación entre unas personas con lenguas, culturas y procedencias tan diversas, vinculadas sobre todo por negocios, se fue transformando paulatinamente en lengua materna de una nación. Las distintas lenguas encontradas en la isla ejercieron influencias mutuas y dieron a luz a una nueva. No obstante, según explica Munteanu (1996: 136), «la influencia de una lengua sobre otra u otras se ejerce de manera variable, en proporción directa con el grado de cultura y civilización representado por dicha lengua». Con más precisión esto quiere decir que el estatus social de los

2 Las islas Aruba, Bonaire y Curazao son conocidas también como las islas ABC. 
grupos involucrados en el proceso determinará cuál de las dos (o más lenguas) recibirán la influencia y cuál será la que la ejercerá.

Indudablemente, después de una presentación breve de la historia queda claro que el español, particularmente, la variedad diatópica del español americano y el español de los colonos llevados en los albores del siglo XVI, junto al holandés tuvieron un gran protagonismo en cuanto a la formación del papiamento por la prolongada convivencia y la porosidad que existía entre varias comunidades y sus lenguas. Asimismo, es evidente la notable presencia de los sefardíes, hecho que hizo que se integraran palabras del español y portugués. Así, el papiamento iba incorporando léxico que le faltaba para la comunicación diaria y más compleja de diferentes fuentes pero, porcentualmente hablando, destacan sobre todo las palabras adoptadas del español, holandés y portugués.

Sin embargo, para que se cristalice y desarrolle una nueva lengua tienen que darse ciertas condiciones que según Weinreich (en Munteanu, 1996: 150, 151) son, en primer lugar, «las lenguas en contacto deben presentar diferencias suficientemente grandes para que el nuevo idioma sea sustancialmente distinto de las lenguas de input»; en segundo lugar, «[...] hay que superar la estricta casualidad lingüística [...] en otras palabras, después de un periodo de fluctuaciones, es necesario que se llegue a cierta estabilidad de forma»; en tercer lugar, «el ambiente sociocultural donde se habla la respectiva lengua tiene que ser relativamente amplio, [es decir, tiene que] superar una esfera restringida de comunicación [...]»; y por último, «el hablante debe tener una clara consciencia sociolingüística». Todas estas condiciones las tenía el papiamento siendo apenas un embrión, lo cual hizo que en un determinado momento cogiera su propio sendero, en el que experimentó una evolución interna propia, haciendo de éste, actualmente, una lengua aparte.

El camino recorrido por el criollo hacia la «afirmación plena de su personalidad como lengua de un pueblo» (Álvarez Nazario en Munteanu, 1996: 48) no fue un camino nada fácil, ni le faltaron obstáculos. Fueron muchos años que pasó escondiéndose en las sombras de las lenguas que llevaron los conquistadores a las islas, se hablaba clandestinamente, hasta que finalmente le fue concedido el estatus de lengua oficial en $2007^{3}$. Lo cual, por cierto, es algo sumamente singular ya que entre los criollos en el territorio caribeño no es algo usual. Hoy día tiene su propia literatura, sus normas ortográficas establecidas, su gramática y sus diccionarios. Forma parte de la enseñanza obligatoria de todos los colegios e institutos, se da como materia universitaria en

3 En Aruba el papiamento es lengua oficial desde el año 2004. 
la Universidad de Curazao además de que posee sus propios medios de comunicación, tanto escritos como también audiovisuales.

\section{Introducción a la literatura del papiamento y a su principal protagonista: una araña sabia llamada Nanzi}

Los cuentos de Kompa Nanzi emanaron de la creatividad de un pueblo africano en Ghana llamado Ashanti y fueron llevados al Nuevo Mundo con la trata de esclavos. No queda ninguna duda de que son muy viejos y normalmente tienen por tema principal el hambre y el poder de un superior que se ven reflejados en casi todos los cuentos. Sin embargo, nadie sabe cuándo exactamente surgieron.

La serie más conocida está formada de los cuentos de Kompa Nanzi que es una «figura común en el folklore de varios pueblos de la región caribeña» (Munteanu, 1996: 51) lo cual es perfectamente explicable con la historia de este territorio: el comercio de los esclavos que llegó hasta partes tan lejanas como Brasil, en el sur, y hasta el sur de EE.UU., en el norte. Según explica Joubert (en Munteanu, 1996: 51) se trata en realidad de Ananse de la Costa de Oro de África, «criollizado bajo las formas Ananzy, en Surinam, Unancy, en Jamaica, o Auntie Nancy, en el sur de los EE.UU.». El protagonista de estos cuentos es, por lo general, una araña perezosa pero sabia que se aprovecha de la ingenuidad de los demás engañándoles. El hecho de que estos cuentos se extendieran por un territorio muy amplio, ha sido razón de peso por la que se manifiestan algunas diferencias entre las narraciones. Así, por ejemplo, en Surinam Nanzi se llama Anansi, su mujer en vez de Shi Maria es Akoeba y en Surinam tienen doce hijos y no nueve como en Curazao.

A pesar de tener una larga tradición, no es sino en el siglo XIX cuando los cuentos empiezan a ponerse por escrito: en las islas $\mathrm{ABC}$ en papiamento, en sranan tongo en Surinam y en otras lenguas criollas de la región del Caribe. En Curazao la primera recopilación de una cantidad considerable de estos cuentos de la araña sabia fueron publicados por Nilda Geerdink-Jesurun Pinto en 1952 bajo el título Cuentanan di Nanzi y justamente siete de los cuentos de esta obra fueron el objeto de análisis del vocabulario para estudiar así las distintas influencias sobre el léxico del papiamento.

Muchas veces los cuentos esconden una crítica indirecta de los que tenían el poder en sus manos, ya que en realidad estos cuentos representaban el único modo de escape. Claro está que se narraban y transmitían secretamente 
porque a los esclavos no se les permitía vivir su cultura ni utilizar su lengua en las plantaciones, con lo que estos cuentos simbolizaban para ellos la libertad y la esperanza de algún día poder ser libres.

\subsection{Análisis del léxico}

Los cuentos de la obra Kon Nanzi a nèk Shon Arei i otro kuentanan antiano di e araña sabí, recopilados y transcritos por Geerdink-Jesurun Pinto, publicada en 2012 por Drukkerij Slinger en Alkmaar (Holanda) que fueron seleccionados para este análisis del léxico son:

1. Kompa Nanzi i Kompa Tiraleu5 (pp. 25-35);

2. Shon Arei ku Kompa Nanzi (pp. 66-69);

3. Kon Nanzi a nèk Diabel (pp. 70-74);

4. E pustamentu di Nanzi (pp. 75-79);

5. Sbon Arei ta duna Nanzi un pida tera (pp. 105-109);

6. Nanzi ku Koma Warawara (pp. 110-119);

7. Skupi di Nanzi (pp. 180-190).

Los temas tratados en estos siete cuentos reflejan sobre todo la escasez de comida y, consiguientemente, el sufrimiento causado por el hambre y la pobreza. Asimismo está presente el poder de alguien superior, lo cual son claros indicadores de la impotencia y el maltrato sufridos por los esclavos.

Algunos cuentos contienen una moraleja pero no siempre es el caso ya que muchas veces el engaño y la maldad quedan impunes. Es más, a veces el camino fácil, el sin mucho esfuerzo es presentado como el modo habitual para conseguir las cosas que se quieren en la vida o incluso es premiado.

A continuación sigue un análisis del vocabulario de estos cuentos que fueron seleccionados especialmente por su interesante contenido léxico. Sin embargo, no todo el vocabulario de los siete cuentos en cuestión fue objeto del análisis por razones de espacio.

Todos los ejemplos van marcados con el número del cuento del que proceden (de acuerdo con el número designado en este artículo) y el número de página del libro original (Geerdink-Jesurun Pinto, 2012). Por ejemplo: áwaseru (1:

4 La traducción del título es mía: Como Nanzi engañó al Don Rey y otros cuentos antillanos de esta araña sabia.

5 Mis traducciones de los títulos en cuestión son: El compadre Nanzi y el compadre Arrojalejos; El señor rey y el compadre Nanzi; Como Nanzi engañó al Diablo; La apuesta de Nanzi; El rey le da a Nanzi un pedazo de tierra; Nanzi y la comadre Águila; y, El escupitajo de Nanzi. 
25). El número uno significa que el ejemplo está sacado del primer cuento: Kompa Nanzi i Kompa Tiraleu, y el número 25 hace referencia a la página del libro Kon Nanzi a nèk Shon Arei i otro kuentanan antiano di e araña sabí. Si un determinado ejemplo aparece más de una vez en los cuentos se lo marca una sola vez. Pero antes de pasar al análisis, cabe resaltar una investigación etimológica llevada a cabo por Maduro (en Munteanu, 1996: 412) quien, después de haber analizado un total de 2.426 palabras que según el autor forman el léxico básico del papiamento, concluyó que el $28 \%$ es de origen holandés, el $25 \%$ es de origen claramente español, el $28 \%$ bien podría provenir sea del español sea del portugués, el $4 \%$ es de clara proveniencia portuguesa, el 3,5\% viene del gallego, el $3,5 \%$ podría ser calificado como portugués o como gallego, el $2 \%$ podría ser del portugués, del español como también del gallego y por último, el $6 \%$ es de otros orígenes.

\subsubsection{Origen español}

Así, indudablemente tienen origen español palabras como shelu (1:25) ( $\longleftarrow$ cielo) que por evolución propia y la influencia de la $[s]+$ yod o [i] adquiere una consonante fricativa y palatal /š/ que el español actual desconoce, shete (3:

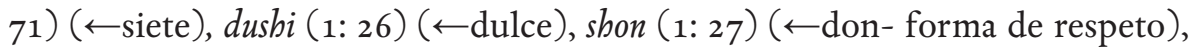

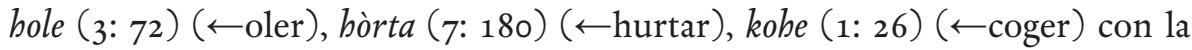
aspirada glotal sorda /h/ que conocía el español de siglo XVI y a comienzos del XVII. También vienen del español yora ( $\leftarrow$ llorar) (1: 25), yega (1: 26) ( $\leftarrow$ llegar) o yen (1: 110) ( $\leftarrow$ lleno), pero por el yeísmo, es decir, la pérdida del fonema español peninsular líquido lateral palatal $/ K /$ se adapta la escritura,

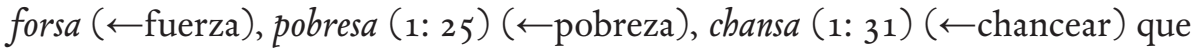
por la pérdida del fonema fricativo intercdental sordo $/ \theta /$ se escribe con una $s$. Es decir, ocurre el seseo ${ }^{6}$. Por lo general, hay que destacar que por la evolución propia tienden a cerrarse las vocales la $o \rightarrow u$ y la $e \rightarrow i$.

Otras palabras se introdujeron sin cambios algunos: pan (1:25) (־pan), tripa (1:31) ( $\leftarrow$ tripa), miseria (1:25) ( $\leftarrow$ miseria) mientras que algunas experimentaron cambios leves para adaptarlas a la escritura y a la fonética del papiamen-

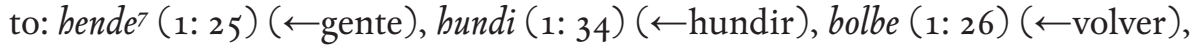

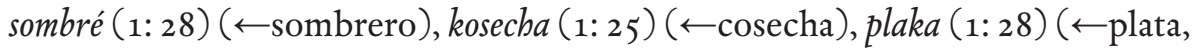

6 La sustitución del fonema $/ \theta /$ por $/ \mathrm{s} /$ es denominado seseo. «En amplias regiones de habla española, tanto en España como en Hispanoamérica, se desconoce este fonema que, por razones de fonética histórica fue sustituido por /s/» (Quilis, 2002: 57).

7 Si hende (gente) va acompañado del adjetivo grandi (*gente grande): bende grandi (1: 34) adquiere significado de adultos. 
pero con el significado de dinero), un bon ratu ( $\leftarrow$ un buen rato), wesu (7: 185) ( $\leftarrow$ hueso), binka (1: 26) ( $\leftarrow$ hincar: «introducir o clavar algo en otra cosa» (DRAE, en línea: $s / n)$ ), golos (1: 26) (Łgoloso). Asimismo viene del español la palabra marchitá (1: 25) ( $\longleftarrow$ marchitar) pero la a final enfatizada significa que ejerce el papel de un adjetivo como también es el caso de los siguientes ejemplos bambrá ( $\leftarrow$ hambriento/a), delegá ( $\longleftarrow$ delgado/a).

En papiamento el árbol es palu (1: 26) (del español palo: «Cada uno de varios árboles o arbustos, generalmente de América del Sur. Palo santo. Palo brasil» (DRAE, en línea: $\mathrm{s} / \mathrm{n}$ ). Así que se trata muy probablemente de una influencia del español americano.

La palabra laira (1: 30) es una asimilación del artículo español con la palabra aire, al igual que quedan restos petrificados de los artículos españoles en, por ejemplo, la palabra: laman (6:118) (la mar), o la asimilación de patras (3:72) ( $\leftarrow$ para atrás), pafo ( $\leftarrow$ para afuera), sinbèrgwensa (7:189) viene de la unión de sin + vergüenza y tiene el mismo significado que en español, pokopoko (1:27) es una asimilación de la variante española poco a poco. Un dicho que entró en papiamento literalmente del español, incluida la forma española de subjuntivo es Satanas sea surdu! (7: 188) (literalmente traducido: ¡Satanás sea sordo!) significa No llames al diablo, porque puede aparecer.

Ora Cha Tiger a lanta pa bai kas, Nanzi a regal'é un pida yòrki basta grandi. (7: 181) (Cuando Cha Tigre se levantó para irse a casa, Nanzi le regaló un pedazo bastante grande de carne.) Aquí muy probablemente yorki (7:189) viene de la palabra española jamón de york pero que en papiamento hace referencia a carne, especialmente de cabra, conservada en sal.

\subsubsection{Origen portugués}

De origen portugués son palabras como pai (1:25) ( $\leftarrow$ pai: padre), mai (1:25) ( $\leftarrow$ mãe: madre), buraku (1:26) (buraco: hoyo), tambe (1: 34) ( $\leftarrow$ também: también), lembe (1:26) (Łlamber: lamer), galiña (3: 71) ( $\leftarrow$ galinba: gallina), kalafriu (3: 72) ( $\leftarrow$ calafrio: escalofrío), papiamentu (2: 34) (sustantivo derivado del verbo portugués papear + -mentu un sufijo muy habitual para formar sustantivos; significa el babla).

8 Es más probable que esta palabra sea de origen portugués y no español (escalofrío). Jacobs, quien reconoce que la mayor influencia sobre el papiamento fue del español, hizo un análisis extenso sobre la contribución del portugués y afirma que esta voz proviene del portugués (2013: 159). 


\subsubsection{Origen español o portugués}

De origen sea español sea portugués son palabras como desepshoná (1: 30) ( $\leftarrow$ decepcionado), zona (1: 27) ( $\leftarrow$ sonar), zeta (2: 66) ( $\longleftarrow$ del español aceite o del portugués azeite), abrenunsia (6: 118) ( $\longleftarrow$ abrenuncio, la interjección coloquial «para dar a entender que se rechaza algo» DRAE, en línea: $\mathrm{s} / \mathrm{n}$ ), ripará (6: 111) ( $\leftarrow$ del español o del portugués reparar: darse cuenta), bun-

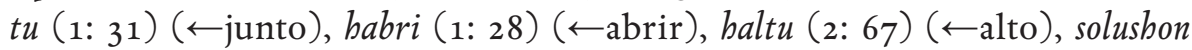

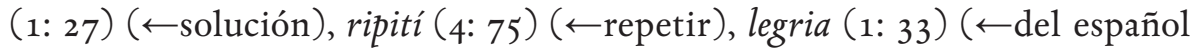

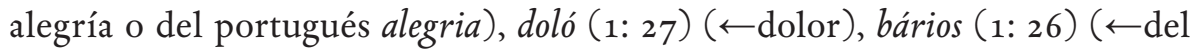
español varios o del portugués vários), sklama (1:35) ( $\leftarrow$ exclamar), bèrdè (1: 28) ( $\leftarrow$ verde), lansa (1: 28) ( $\leftarrow$ del español lanza o del portugués lança), brasa (6: 116) ( $\longleftarrow$ del español brazo o del portugués braço), bendedó (1: 29) ( $\leftarrow$ vendedor), kompèr (1: 30) (Łcompadre), stoma (6:116) (del español estómago o del portugués estômago), pata (1:33) ( $\leftarrow$ pata), kabritu (1:34) ( $\leftarrow$ cabrito), karamba (4: 79) ( $\leftarrow$ de la interjección caramba, eufemismo de carajo), stoba (7: 181) ( $\longleftarrow$ estofado (el participio del verbo estofar, estofar/estufar en portugués), sirvidó (2:66) («servidor), porko (1:34) ( $\longleftarrow$ porco; es desusado en castellano según el diccionario DRAE (en línea: $s / n$ ) ya que fue sustituido por puerco; porco en portugués). Tera $(5: 105)$ ( $\leftarrow$ del español tierra o del portugués terra) que convierte la vibrante múltiple en una simple. Se trata de un fenómeno difundido en variedades diatópicas del español americano, en el español de Guinea, en Filipinas, en el judeoespañol y en los criollos de base hispánica. También ariba (1: 26), del adverbio de lugar (del español arriba o portugués arriba), que al pasar al papiamento pierde una $r$. Por influencia del arahuaco-taíno se dobla el adverbio para darle un significado de por todo lo alto: «El a pasa su man ariba ariba di e palu» (1: 26) significa: Pasó/ Ha pasado su mano por lo más alto del árbol. Otro ejemplo de unión y reiteración es la palabra mei (mitad, del portugués meio) y se convierte en meimei (1:26) lo cual significa en medio de.

Asimismo, vienen de alguna de las dos lenguas las palabras áwaseru (1:25) ( $\leftarrow$ aguacero) o awa (1: 25) ( $\leftarrow$ agua) que sufren una reducción de los grupos consonante $+/ \mathrm{w} /$.

La palabra makaku (1:34) existe en castellano, pero según el DRAE (en línea: $\mathrm{s} / \mathrm{n}$ ) macaco «viene del portugués macaco, voz del Congo, que designa una especie de mono». Así que la palabra tampoco sería portuguesa y se trataría de la influencia de las lenguas africanas, pero pudo haber entrado por las tres vías al papiamento. 


\subsubsection{Origen arahuaco-taíno}

De origen arahuaco-taíno vienen palabras como kadushi (1:25) que es un cacto muy común en las islas $\mathrm{ABC}$ y su nombre latino es Careus rapandus; watapana (4: 75) (un sinónimo utilizado sobre todo en Aruba del árbol dividivi, en latín Caesalpinia coriaria) o la palabra kunuku (1:25) (granja) (de la palabra conuco que según el DRAE (en línea: $\mathrm{s} / \mathrm{n}$ ) en Antillas es una «porción de tierra que los indios taínos dedicaban al cultivo»).

Un ave muy típica para la región conocida en español como chingolo o chincol (en latín Zonotrichia capensis) viene del arahuaco-taíno añadiéndole el sustantivo gai (6: 111) (gallo), en papiamento da chongorogai (4: 76). Asimismo se estima que otro pájaro típico para estas zonas, chuchubi (4: 76) (en latín Mimus gilvus), tiene raíces etimológicas en esta lengua indígena, conocido como chouchoubitu.

\subsubsection{Origen holandés}

Del holandés vienen palabras como zuai (1: 33) ( $\leftarrow$ zwaaien: oscilar), feter

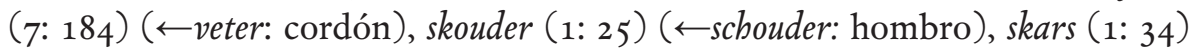

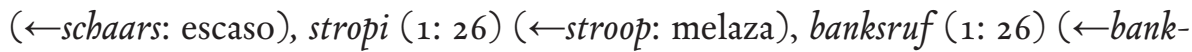
schroef: tornillo), lòs (1: 26) («los: suelto), stèm (1: 27) (stem: voz), graf (1:

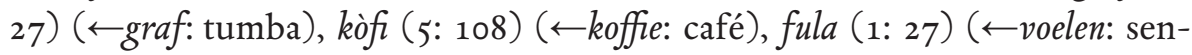

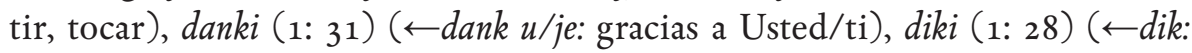
gordo, grueso), boncbi (2: 66) ( $\leftarrow$ bonen: judías), duars (2: 66) ( $\leftarrow d$ wars: diagonal, transversal), rònt (1: 26) ( $\leftarrow$ rond: alrededor de, redondo), pòcbi di leim ( 3 :

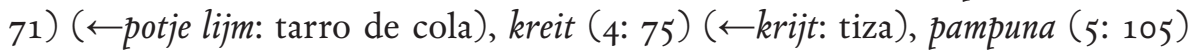

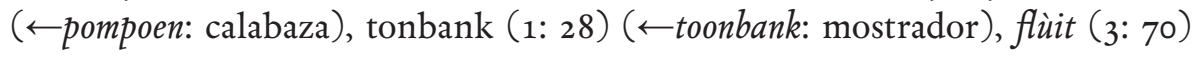

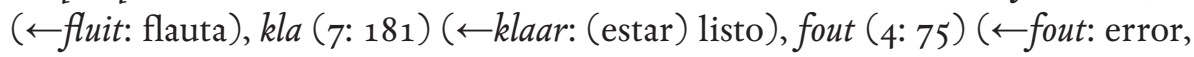
equivocación), planchi (5: 105) ( $\leftarrow$ plantje: diminutivo de planta, plantita).

El papiamento adaptó algunas estructuras del holandés como por ejemplo: kai flou (1: 25), del holandés flauwvallen (desmayarse); laga lòs (1: 35) (Łlaat los (infinitivo: loslaten) y es imperativo que significa deja/deje); na repi repi (5: 106) ( $\longleftarrow$ in reepjes: en pequeños pedazos) que por la influencia de la lengua indígena, experimenta redoblamiento.

Se funden también algunos sustantivos con el artículo no sólo del español también del holandés: delaster (1: 33) ( $\longleftarrow$ de laatste: el último/la última).

El papiamento adopta algunos dichos del holandés, como por ejemplo, Esun ku koba un pos pa otro, e mes ta kai aden (1:35) (Wie een kuil graaft voor een ander, 
valt er zelf in que significa: Cae en la cueva el que a otro a ella lleva). En este dicho se sustituye kuil (cueva) por la palabra pos que viene del español pozo. Pero, por otra parte se utiliza del holandés el verbo graaft ( $3^{\text {a }}$ persona del singlar del infinitivo: graven) (koba: cavar y no llevar). El verbo wak (1: 30) (ver, mirar) viene del verbo holandés waken que significa velar, vigilar, proteger lo cual asimismo podría ser explicado por las circunstancias de esclavitud.

\subsubsection{Otros orígenes e influencias}

El último apartado está dedicado a unas palabras que no encajan en ninguno de los apartados arriba mencionados sino que son provenientes de lenguas africanas, del inglés, del holandés antiguo, o tienen otros orígenes, como por ejemplo: funchi ( $1: 25)$, que es un tipo de polenta, harina de maíz, que acompaña muchos platos antillanos. Se estima que proviene de un vocablo angoleño: nfunji lo cual significa papa de casabe. Se conoce también en Cuba y Puerto Rico como funche: «Especie de gachas de harina de maíz» (DRAE, en línea: $s / n$ ).

La palabra guiambo (5: 105) (en latín Abelmoscbus esculentus) probablemente proviene de una voz africana ki' ngogombo, en español quimbombó, en Cuba y Venezuela conocida como quingombó, y según el DRAE (el línea: s/n) se trata de una

planta herbácea originaria de África y cultivada en América, de la familia de las Malváceas, de tallo recto y velludo, hojas grandes y flores amarillas, parecidas a las del algodonero, y fruto alargado, casi cilíndrico y lleno de semillas que al madurar toman un color oscuro. El fruto tierno se emplea en algunos guisos, dando una especie de gelatina que los espesa, y también en medicina. La planta, que es filamentosa, se emplea como textil. (DRAE)

Si la palabra entró en papiamento a través del español, portugués o gallego, o si es influencia directa de las lenguas africanas, no se sabe muy bien, ya que bien podrían ser por las cuatro vías, dado los hechos históricos.

El término, cbincbirincbi (7: 187), utilizado para denominar un gorrión (Passer domesticus) proviene de un nombre de origen africano que en África significa una flor: chinchirinchee ${ }^{9}$ (de la familia Asparagaceae forma parte del grupo de

9 Según el diccionario Merriam-Webster (en línea: s/n) se trata de «a southern African perennial bulbous berb (Ornithogalum thyrsoides) of the lily family with spikes of white to goldenyellow blossoms». 
Ornithogalum, y existen alrededor de 180 especies), en español conocida como estrella de Belén.

Entra al papiamento smoking (1: 28) una palabra inglesa (smoking), sin embargo, no está claro si es un préstamo directo del inglés, o si entra a través del holandés o del español, ya que las dos lenguas conocen esta palabra con la escritura inglesa ${ }^{10}$. También muf (6:111) probablemente viene del inglés ( $\leftarrow$ move: mover) o bèk (6:111) ( $\leftarrow$ back: de vuelta, de regreso), y la palabra que indudablemente sí tiene origen inglés es djap (7: 181) ( $\longleftarrow j o b$ : trabajito).

De origen holandés antiguo viene tayó (7: 181) (plato) que viene del holandés antiguo teljoor y mankaron (7: 188) que viene de la antigua palabra holandesa makkaroen que, según la enciclopedia Encyclopaedie van Nederlandsch West-Indië (1914-1917), significaba esclavo no apto para ser vendido porque tenía más de 35 años, padecía de alguna enfermedad, tenía el pelo canoso o le faltaba algún diente ${ }^{11}$. Hoy se utiliza en papiamento para algo o alguien que tiene algún defecto.

Palabras de difícil clasificación son: bariña (1:25) que bien podría ser del español harina, del portugués farinba o del gallego que conoce dos variantes: fariña y barina. El lingüista Bart Jacobs (2013: 162), afirma que se trata de una mezcla de los lexemas del portugués y del español. El vocablo paña (2: 66) (ropa) tampoco parece tener un origen claro, tal vez del español paño que según DRAE (en línea: $\mathrm{s} / \mathrm{n}$ ) significa «tela de diversas clases de hilos».

El sustantivo toalla en papiamento es sèrbète (2: 66) y claramente no viene del español, ni del portugués (toalha), como tampoco del holandés banddoek. Una posible relación podría establecerse con la palabra francesa serviette. La palabra eskeleto (1:25) bien podría venir del español (esqueleto), portugués

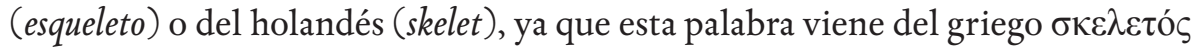
y significa desecado.

Para las palabras como: mondi (1: 29) (bosque), baña (1: 26) (obtener), no se ha encontrado una conexión, como tampoco para lombra (1:35) (brillar, resplandecer), tende (1: 35) (escuchar), dòp (1:25) (remojar), garoshi (1: 31)

10 El español también admite la variante esmoquin, pero las dos ortografías son válidas según el diccionario Clave (en línea: $\mathrm{s} / \mathrm{n}$ ), smoking o esmoquin.

11 Encyclopaedie van Nederlandsch West-Indië (en línea: $\mathrm{s} / \mathrm{n}$ ): «Bonkjes of makkaroens noemde men in den tijd van den slavenhandel -in tegenstelling van de Pieças d'India of leverbaren-de negers die niet leverbaar, n.l. boven de 35 jaar oud, verminkt of aan ziekten onderbevig waren, die grijze baren badden of eenige tanden misten». 
(caretilla), flus $(1: 28)$ (traje $\left.{ }^{12}\right)$ lo cual podría confirmar que el papiamento también creó palabras propias.

\section{Conclusión}

El papiamento, un mero pidgin que paulatinamente se fue transformando en lengua adquirida, en la lengua materna de una nación, es fruto de muchos siglos de haber existido, de haberse ocultado en las sombras de las lenguas europeas de los conquistadores y que en el año 2007 obtuvo el estatus de lengua cooficial. A su paso fue recogiendo, como una esponja, un sinfín de influencias que las fue insertando harmónicamente en un conjunto pero a su vez también por ser poroso dejó escapar alguna que otra influencia a las lenguas en contacto.

Concluimos estas reflexiones sobre el papiamento comparándolo a un árbol. Es una bella metáfora que dice: unas semillas de diferentes tipos cayeron en la tierra poco cultivada de una isla caribeña de las cuales y con el paso del tiempo nació un árbol fuertemente arraigado con un tronco hispánico, ramas holandesas, arahuaco-taínas, africanas, portuguesas, judeoespañolas, gallegas y algún que otro injerto francés e inglés, sin embargo, la única fruta que se cosecha de este desigual árbol es el papiamento.

\section{Bibliografía}

Alvar, M. (1996): Manual de dialectología bispánica. El español de América. Barcelona: Editorial Ariel

Benjamins, H. D. en Snelleman, J. F. (1914-1917): Encyclopaedie van Nederlandsch West-Indië. Den Haag/Leiden, Martinus Nijhoff/E.J. Brill. http://www.dbnl.org/tekst/benjoo4encyo1_01/benjoo4ency01_01_0005. php\#a0568 [consultado: 24.03.2015]

Choghari, M. (2015): El papiamento - un criollo bispánico. Papiamento - Španski kreolski jezik. Magistrska naloga (Tesis de maestría inédita). Ljubljana: Filozofska fakulteta

Crystal, D. (1994): Enciclopedia del lenguaje de la Universidad de Cambridge. Madrid: Taurus Ediciones.

García L., David L. (2011): «Las lenguas criollas del Caribe: Orígenes y situación sociolingüística, una aproximación». En Forma y función, vol. 24, núm. 2, julio-diciembre. Bogotá: Universidad Nacional de Colombia. http:// www.redalyc.org/artículo.oa? id=21925446003 [consultado: 20.10.2014]

12 Se trata del sustantivo masculino, singular (el traje). 
Geerdink-Jusurun Pinto, N. (2012): Kon Nanzi a nèk Shon Arei i otro kuentanan antiano di e araña sabi. Hoe Nanzi de koning beetnam en andere Antilliaanse verbalen over de slimme spin. Curazao: Instituto Raúl Römer.

Hermano Saraiva, J. (2004): História de Portugal. Mem Martins, Publicações Europa- América, LDA.

Jacobs, B. (2012): «Linguistic evidence and histography: the selection of slaves on Curaçao, 1650-1700». En Revista de Crioulos de Base Lexica Portughesa e Espabnola. Universität Konstanz \& Radboud Universiteit Nijmegen

http://media.leidenuniv.nl/legacy/jacobs-2012-linguistic-evidence-and-historiography-the-selection-of-slaves-on-curacao\% $2 \mathrm{C}-1650-1700 . p d f$ [consultado: 04.11.2014]

Jacobs, B. (2013): «Reassessment of the Portuguese contribution to the Papiamentu lexicon». En Journal of Pidgin and Creole languages (28: 1), 154165. Universität Konstanz \& Radboud Universiteit Nijmegen. http:// media.leidenuniv.nl/legacy/jacobs-2013-reassessment-portuguese-contribution-to-papiamentu-lexicon.pdf [consultado: 28.03.2015]

Lipski, J. M. (2003): «Contacto de lenguas en el Caribe hispánico: implicaciones para el español caribeño» (43-60) http://www.personal.psu.edu/ jml34/cont.pdf [consultado: 1.4 .2015 ]

Lipski, J. M. (2004): «Las lenguas criollas de base hispana» en Lexis XXVIII. 1-2. http://www.revistas.pucp.edu.pe/index.php/lexis/article/viewFile/ 9199/9608 [consultado: 27.10.2014]

Martinus Arion, F. (2011): Dubbelspel. Steenwijk: Drukkerij Bariet Ruinen.

Medina López, J. (1997): Lenguas en contacto. Madrid: Arco Libros.

Munteanu, D. (1996): El papiamento, lengua criolla bispánica. Madrid: Editorial Gredos.

Munteanu, D. (1996): «Papiamento». En Manual de dialectología bispánica. El español de América. Barcelona: Editorial Ariel.

Munteanu Colán, D. (2009): «Cohesión textual y relación genética: el caso del papiamento». En RRL, LIV, 3-4. 307- 318. http://www.lingv.ro/RRL\%20 3-4\%202009\%20Munteanu\%2oColan.pdf [consultado: 25.03 .2015 ]

Sijs, N. van der (2006): Klein uitleenwoordenboek. http://www.etymologiebank. $\mathrm{nl} /$ [consultado: 25.03 .2015 ]

Universidad de Leiden (2007): «Papiaments officieel erkend» http://www.leidenuniv.nl/nieuwsarchief 2/1478.html [consultado: 19.09.2014] 
Velleman, B. L. (2008): «La imagen y los ecos del lingüista profesional: La correspondencia de Rodolfo Lenz». En RLA, Revista de Lingüística Teórica y Aplicada. 46 (1), I Sem. Concepción (Chile). http://www.scielo. cl/scielo.php?'script=sci_arttext\&pid=So718-48832008000100002 [consultado: 17.10 .2014$]$

VV.AA. (2015): Diccionario Clave. http://www.smdiccionarios.com/home. php [consultado: 26.03 .2015 ]

VV.AA. (2014): Diccionario de la Real Academia de la lengua española. http://rae.es [consultado: 28.10.2014]

VV.AA. (2015): Diccionario de Merriam-Webster. http://www.merriam-webster.com/inter? dest=/info/index.htm [consultado: 25.03 .2015 ]

VV.AA. (2015): Word reference. Diccionarios online de idiomas. http://www.wordreference.com/ [consultado: 22.03.2015] 


\section{Maya Choghari}

University of Ljubljana

\section{The Papiamento - a linguistic treasure}

Key words: Papiamento, creole, history, text analysis, Kompa Nanzi.

Papiamento, a creole language spoken by approximately 200.000 people on three Caribbean islands, Aruba, Bonaire and Curacao, has recently acquired official status and has been recognized as an official language, besides the Dutch in the Kingdom of The Netherlands.

However, the privilege, which it enjoys today, is a result of many centuries of generations speaking it clandestinely and Papiamento had always been forced to subsist in the shadows of the languages spoken by its colonizers, mostly Spanish and Dutch.

Overall, this particular language contains traces of ancestral Arawak people, its native population, African influences brought to the island of Curacao, which was one of the biggest slave ports during centuries, as well as the influence of Portuguese and French but mostly of Dutch and Spanish.

In this great melting pot, people created this language in order to communicate with each other but it always had a secondary role, with its literature, its culture hidden until recently. However, what used to be just a pidgin at first turned into a mother tongue of a nation, conferring on Papiamento the status of a creole language.

The main objective of this article is to expose the history, the evolutions and the different influences, that contributed to the formation of this creole, which despite some controversies, is a Hispanic creole language. Seven stories have been selected to be analyzed in order to show the different influences in the Papiamento's vocabulary and to reaffirm that Papiamento is a Hispanic creole language. 


\section{Maya Choghari}

Univerza v Ljubljani

\section{Papiamento - lingvistični zaklad}

Ključne besede: papiamento, kreolski jezik, zgodovina, besedilna analiza, Kompa Nanzi

Papiamento je kreolski jezik, ki ga govori približno 200.000 ljudi na treh karibskih otokih, Arubi, Bonairu in Curaçau, in si je pred kratkim izboril status drugega uradnega jezika, poleg nizozemščine, v Kraljevini Nizozemski. Privilegij, ki ga ima danes, je rezultat generacij, ki so bile prisiljene ta jezik več stoletij uporabljati na skrivaj, v senci jezikov, ki so jih prinesli s seboj kolonizatorji, predvsem Španci in Nizozemci.

Jezik vsebuje vidne sledi avtohtonega prebivalstva Arawakov, afriških jezikov, ki so prispeli na otok Curaçao, ko je bil dolga stoletja eno največjih pristanišč sužnjev, ter različnih vplivov portugalskega, angleškega in francoskega jezika, predvsem pa nizozemščine in španščine. Ta unikatna sobivajoča mešanica ljudi je ustvarila jezik z namenom, da bi se lahko sporazumevali. Gre za pidžinski jezik, ki se je skozi stoletja spremenil v materni jezik naroda. Od tistega trenutka naprej se govori o kreolskem jeziku, vendar pa je imel dolga stoletja stransko vlogo. Tako sta bili njegova literatura in kultura do nedavnega potisnjeni na rob. Glavni cilj tega članka je osvetliti zgodovino, evolucijo in različne vplive, ki so prispevali k nastanku tega edinstvenega jezika, ki je pravi lingvistični zaklad. Prek sedmih izbranih zgodb Kompa Nanzi želi članek osvetliti različne vplive, ki so vidni v jeziku, ter posledično dokazati teorijo, da je papiamento kljub številnim polemikam kreolski jezik španskega izvora. 